This item was submitted to Loughborough's Research Repository by the author.

Items in Figshare are protected by copyright, with all rights reserved, unless otherwise indicated.

\title{
Effect of breakfast omission on energy intake and evening exercise performance
}

PLEASE CITE THE PUBLISHED VERSION

http://dx.doi.org/10.1249/MSS.0000000000000702

\section{PUBLISHER}

(C) Lippincott, Williams and Wilkins

\section{VERSION}

AM (Accepted Manuscript)

\section{PUBLISHER STATEMENT}

This work is made available according to the conditions of the Creative Commons Attribution-NonCommercialNoDerivatives 4.0 International (CC BY-NC-ND 4.0) licence. Full details of this licence are available at: https://creativecommons.org/licenses/by-nc-nd/4.0/

\section{LICENCE}

CC BY-NC-ND 4.0

\section{REPOSITORY RECORD}

Clayton, David, Asya Barutcu, Claire Machin, David Stensel, and Lewis James. 2015. "Effect of Breakfast Omission on Energy Intake and Evening Exercise Performance". Loughborough University.

https://hdl.handle.net/2134/20480. 


\section{Effect of breakfast omission on energy intake and evening exercise performance}

2 David J. Clayton ${ }^{1}$, Asya Barutcu ${ }^{1}$, Claire Machin ${ }^{1}$, David J. Stensel ${ }^{1}$, \& Lewis J. James ${ }^{1}$ *

3

$4{ }^{I}$ School of Sport, Exercise and Health Sciences, Loughborough University, Loughborough,

$5 \quad$ Leicestershire, LE11 3TU, UK

6

$7 \quad$ *Corresponding author: Dr Lewis J. James

8 Email: L.James@lboro.ac.uk

$9 \quad$ Tel: $+44(0) 1509226305$

10 Fax: +44 (0) 1509226301

11

12

13

14

15 
$\underline{\text { Abstract }}$

Introduction: Breakfast omission may reduce daily energy intake. Exercising fasted impairs performance compared to exercising after breakfast, but the effect breakfast omission has on evening exercise performance is unknown. This study assessed the impact of omitting breakfast on evening exercise performance, as well as within-day energy intake. Methods: Ten male, habitual breakfast eaters completed two trials, in randomised, counterbalanced order. Subjects arrived at the laboratory overnight fasted, and either consumed or omitted a $733 \pm 46 \mathrm{kcal}(3095 \pm 195 \mathrm{~kJ})$ breakfast. Ad-libitum energy intake was assessed at $4.5 \mathrm{~h}$ (lunch) and $11 \mathrm{~h}$ (dinner). At $9 \mathrm{~h}$ subjects completed 30 min cycling exercise at $\sim 60 \%$ $\mathrm{VO}_{2}$ peak, followed by a 30 min maximal cycling performance test. Food was not permitted for subjects once they left the laboratory after dinner until 08:00 the following morning. Acylated ghrelin, GLP-1 $1_{(7-36)}$, glucose and insulin were assessed at 0, 4.5 and $9 \mathrm{~h}$. Subjective appetite sensations were recorded throughout. Results: Energy intake was $199 \pm 151 \mathrm{kcal}$ greater at lunch $(P<0.01)$ after breakfast omission compared to breakfast consumption and tended to be greater at dinner after consuming breakfast $(P=0.052)$. Consequently, total $a d-$ libitum energy intake was similar between trials $(P=0.196)$, with 24 h energy intake $19 \pm 5 \%$ greater after consuming breakfast $(P<0.001)$. Total work completed during the exercise performance test was $4.5 \%$ greater after breakfast $(314 \pm 53 \mathrm{~kJ}$ vs. $300 \pm 56 \mathrm{~kJ} ; P<0.05)$. Insulin was greater during $\mathrm{BC}$ at $4.5 \mathrm{~h}(P<0.05)$, with no other interaction effect for hormone concentrations. Conclusions: Breakfast omission might be an effective means of reducing daily energy intake, but may impair performance later that day, even after consuming lunch.

Key words: Appetite, Energy restriction, Energy balance, Meal omission, Ghrelin, GLP-1 
Maintenance of a stable body weight is achieved through careful management of energy balance, with weight gain occurring due to a chronic surplus of energy intake above energy expenditure. Refraining from eating at a prescribed meal time will inevitably create an energy deficit, and breakfast omission is a frequently cited method of reducing energy intake (40). Regular breakfast consumption has been recommended as part of a "healthy balanced diet" (24) and individuals who regularly consume breakfast tend to have a lower BMI (3) and reduced prevalence of several chronic diseases including type-2 diabetes (26).

Traditionally, recommendations for regular breakfast consumption have been based on correlational studies that associate a lower BMI with regular breakfast consumption (3). However, these findings do not infer causality as individuals who regularly consume breakfast have often been shown to exhibit healthy lifestyle factors, such as increased physical activity (6) and improved dietary profiles (14). Therefore it is difficult to elucidate whether improved weight control is mediated by breakfast consumption per-se.

Acute intervention studies have generally found that the omission of breakfast induces increased feelings of hunger over the morning, leading to greater energy intake in the first meal following breakfast omission $(19,22)$. However, energy intake over the course of the day rarely results in complete compensation for the energy omitted at breakfast, consequently reducing daily energy intake $(2,19,22,25,30)$. Although this is not a universal finding as Astbury et al. (1) found that energy omitted at breakfast was fully compensated for at an adlibitum lunch meal, and Farshchi et al. (11) found energy intake to be greater following breakfast omission compared to breakfast consumption. Whilst investigating a similar topic, one of these studies utilised a liquid pre-load between breakfast and lunch to determine the hormonal response to breakfast omission (1) and the other balanced energy intake by providing cereal and milk at either $07: 00$ or 12:00, representing breakfast consumption and 
omission, respectively (11). These differences in design may explain the contradictory findings in these studies.

Lifestyle interventions that combine both dietary restriction and exercise have been shown to be more effective for long term sustainable weight loss and maintenance (12). Therefore it is important to consider the effect that a given dietary intervention has on physical activity and the ability to perform exercise, as this will influence the magnitude of energy deficit that can be achieved. Recently it was reported that daily energy intake was reduced by approximately $2250 \mathrm{~kJ}$ during a 6 week period of breakfast omission, however this deficit was offset by concomitant decreases in habitual energy expenditure of approximately $1850 \mathrm{~kJ}$ (2). The inclusion of structured exercise during periods of energy restriction may have the potential to somewhat offset this decline in habitual energy expenditure, if exercise performance and/or adherence is not affected as a result of breakfast omission.

A working lifestyle may restrict time for exercise to early mornings or evenings. Evening exercise classes have been associated with increased alertness, enthusiasm and reduced effort than morning classes (23), suggesting that evening exercise may be the more acceptable option and may improve long-term adherence to an exercise program. Furthermore, some athletes have been reported to compete or train without the consumption of breakfast (34) and it is important to consider what the effects of breakfast omission are for individuals aiming to achieve peak exercise performance. Whilst it is well established that exercise performance is compromised in the fasted compared to post-prandial state $(32,33)$, no studies have attempted to determine whether exercise performed later in the day is affected by the prior omission of breakfast.

Therefore the aim of this investigation was to examine the impact of breakfast omission/ consumption on subsequent energy intake and evening exercise performance $4 \mathrm{~h}$ after 
provision of an ad-libitum lunch. We hypothesised that total $24 \mathrm{~h}$ energy intake (including breakfast) would be reduced by breakfast omission and that exercise performance would not be different between trials

\section{Methods}

\section{Subjects}

After ethical approval, subjects completed a medical screening questionnaire and provided written informed consent. Subjects were 10 healthy, weight stable (self-reported), recreationally active $\left(<10 \mathrm{~h} \cdot \mathrm{week}^{-1}\right)$ males (age: $22 \pm 3 \mathrm{y}$, weight: $73.1 \pm 9.7 \mathrm{~kg}$, height: 1.76 $\pm 0.05 \mathrm{~m}$, BMI: $23.5 \pm 3.2 \mathrm{~kg} \cdot \mathrm{m}^{-2}$, Body fat: $\left.17 \pm 6 \%\right)$. Subjects regularly consumed breakfast and were not restrained, disinhibited or hungry eaters determined after completion of a three-factor eating questionnaire (35).

\section{Preliminary trials}

Subjects completed three preliminary trials. During the first trial; height (to nearest $0.1 \mathrm{~cm}$ ), and weight (to nearest $0.02 \mathrm{~kg}$ ) were measured, and body fat percentage was estimated using skin-fold callipers (10). A discontinuous incremental exercise test was also performed on an electrically braked cycle ergometer (Lode Corival, Groningen, Holland) to determine peak oxygen consumption $\left(\mathrm{VO}_{2}\right.$ peak). Increments lasted for $4 \mathrm{~min}$, were separated by $\sim 5$ min rest and increased until volitional exhaustion. Expired air was collected into a Douglas bag during the last min of each increment. Heart rate was measured (Polar Beat, Kempele, Finland) and subjects rated their perceived exertion (RPE) on a 6-20 point scale, at the end of each increment. Expired air samples were analysed for oxygen and carbon dioxide concentration (Servomex, Crowborough, UK), volume (Harvard Dry Gas Meter, Harvard Ltd, Edenbridge, UK) and temperature (Edale, Cambridge, UK). 
During the second preliminary trial, subjects were fully familiarised with the experimental protocol (described in detail below), with the exception that subjects were permitted to come and go from the laboratory between feeding periods and the exercise protocol. On the third preliminary trial, subjects completed the exercise protocol for a second time.

\section{Pre-trial standardisation}

In the $48 \mathrm{~h}$ preceding the first experimental trial, subjects completed a weighed food diary, replicating this in the $48 \mathrm{~h}$ preceding the second trial. Strenuous exercise and alcohol intake were not permitted during this period. Subjects travelled to and from the laboratory via motorised transport, arriving in the morning following an overnight fast of $\geq 10 \mathrm{~h}$.

\section{Protocol}

Subjects completed two experimental trials; breakfast consumption (BC) and breakfast omission (BO). Trials were separated by at least 7 days, conducted at the same time of day, on the same day of the week and were administered in a randomised, counterbalanced order. Subjects were aware that the aims of the study were to assess the effect of breakfast omission on appetite, energy intake and exercise performance, but were not aware of the hypothesis.

Subjects arrived at the laboratory at $\sim 07: 30$, were weighed and a fasted blood sample was collected by venepuncture of an antecubital vein, after a 30 min period of supine rest $(0 \mathrm{~h})$. Baseline measures of subjective appetite sensations on a visual analogue scale were obtained before participants received either a standardised breakfast (BC) or no breakfast (BO). After breakfast $(0.5 \mathrm{~h})$ subjects rested quietly in the laboratory. A second blood sample was drawn at 12:30 (4.5 h), following which a multi-item ad-libitum lunch buffet was served consisting of cold, ready-to-eat foods. Upon termination of the meal, subjects again rested in the laboratory. At 17:00 (9 h) a blood sample was drawn before subjects began the exercise 
protocol (described below). One hour after completion of the performance test $(11 \mathrm{~h})$, an $\mathrm{ad}$ libitum pasta test meal was served. Following the test meal $(11.5 \mathrm{~h})$, subjects were transported home and were instructed not to eat or drink anything other than plain water until they went to bed. Subjects returned to the laboratory after an overnight fast the following morning at 08:00 (24 h) for body mass measurement and to complete a subjective appetite sensations questionnaire. Ad-libitum water and low-energy squash was available on request throughout the study period, and was provided with each buffet meal.

\section{Ad-libitum meals}

Each ad-libitum meal was provided in excess of expected consumption and more food was available on request. The lunch meal consisted of cooked meats, cheese, bread, butter, mayonnaise, salad, fruit, crisps, cereal bars and biscuits (Tesco, Cheshut, UK). The dinner meal consisted of pasta, cheese, tomato sauce and olive oil (Tesco, Cheshut, UK), was homogenous in nature providing $8.01 \pm 0.04 \mathrm{~kJ} \cdot \mathrm{g}^{-1}(14,33$ and $53 \%$ of energy provided by protein, fat and carbohydrate, respectively), and was served as previously described (5). Meals were served in an isolated feeding laboratory with no interaction between subjects and investigators. Subjects were given $30 \mathrm{~min}$ to consume each meal and were explicitly instructed to eat until they felt 'comfortably full and satisfied'. The amount consumed at each meal was quantified by weighing the food before and after consumption, with macronutrient content of foods ascertained from manufacturer values.

\section{Exercise performance}

Subjects began exercise at 17:00 (9 h) and initially performed 30 min steady state cycling at a workload of $\sim 60 \% \mathrm{VO}_{2}$ peak. After $30 \mathrm{~min}$, subjects completed a performance test, during which they were instructed to complete as much work as possible in $30 \mathrm{~min}$. The workload was set at $75 \% \mathrm{VO}_{2}$ peak and subjects were able to manipulate the workload by pressing up or 
down on the bikes control unit. The control unit was completely covered, so that subjects received no feedback related to the workload completed and subjects were not provided any encouragement, although they were able to see the time remaining. During the steady state exercise, expired air was collected between 14-15 and 29-30 min, and heart rate and RPE was obtained at the end of each collection. During the performance test, workload and heart rate were recorded every $5 \mathrm{~min}$ and RPE every $10 \mathrm{~min}$. Energy expenditure and substrate utilisation were calculated from $\mathrm{VO}_{2}$ and $\mathrm{VCO}_{2}$ values using stoichiometric equations (13).

\section{Standardised breakfast meal}

During BC subjects were provided with a standardised breakfast meal of $25 \%$ estimated daily energy requirements, determined by multiplying resting metabolic rate (RMR) (27) by a physical activity level of 1.7 , to account for the exercise component of the trial. Breakfast consisted of crisped rice cereal, semi-skimmed milk, wholemeal bread, margarine, strawberry jam and orange juice (Tesco, Cheshunt, UK), and amounted to $3095 \pm 195 \mathrm{~kJ}$, with 11, 17 and $72 \%$ of energy derived from protein, fat and carbohydrate, respectively. During BO, subjects were provided with a bolus of water for breakfast equal to that contained within the BC trial. Subjects were instructed to consume the entire meal gradually over the 30 min period.

\section{Subjective Appetite Sensations}

Subjects rated their hunger, fullness, desire to eat (DTE) and prospective food consumption (PFC) on $100 \mathrm{~mm}$ visual analogue scales at $0,0.5,2.5,4.5,5,7,9,10,11,11.5,13$, and $24 \mathrm{~h}$. Verbal anchors of 'not at all/ none at all' and 'extremely/ no desire at all/ a lot' were placed at 0 and $100 \mathrm{~mm}$, respectively.

\section{Blood sampling and analysis}


Blood samples $(12 \mathrm{~mL}$ ) were drawn after $30 \mathrm{~min}$ of supine rest, at $0 \mathrm{~h}$ (baseline), $4.5 \mathrm{~h}$ (prelunch) and $9 \mathrm{~h}$ (pre-exercise) via venepuncture of an antecubital vein. Five $\mathrm{mL}$ of blood was immediately mixed with $50 \mu 1$ Dipeptidyl-peptidase 4 inhibitor (DPP4-010, Merck Millipore, Watford, UK) and dispensed into an EDTA tube $\left(1.75 \mathrm{mg} \cdot \mathrm{mL}^{-1}\right)$, for determination of active glucagon like peptide 1 (GLP-1 $\left.{ }_{7-36}\right)$ by ELISA (EGLP-35K, Merck Millipore, Watford, UK). Two and a half $\mathrm{mL}$ of blood was dispensed into an EDTA tube $\left(1.75 \mathrm{mg} \cdot \mathrm{mL}^{-1}\right)$ containing 10 $\mu \mathrm{l} \cdot \mathrm{mL}^{-1}$ blood of a solution of potassium phosphate buffer $(\mathrm{PBS})\left(\begin{array}{lll}0.05 & \mathrm{M}\end{array}\right), \quad P-$ hydroxymercuribenzonic acid (PHMB) $(0.05 \mathrm{M})$ and sodium hydroxide solution $(\mathrm{NaOH})$ $(0.006 \mathrm{M})$ for determination of acyclated ghrelin concentration by ELISA (A05106, Bioquote Ltd, York, UK). Two and a half $\mathrm{mL}$ of blood was dispensed into an EDTA tube (1.75 $\mathrm{mg} \cdot \mathrm{mL}^{-1}$ ) for measurement of blood glucose concentration (GOD-PAP method, Randox Laboratories Ltd, Crumlin, UK) and insulin concentration by ELISA (DX-EIA-2935, Immunodiagnostic Systems, Boldon, UK) .

All samples were centrifuged at $1750 \mathrm{~g}$ for a total of $15 \mathrm{~min}$ in a refrigerated centrifuge $\left(4^{\circ} \mathrm{C}\right)$. After $10 \mathrm{~min}$ of centrifugation, the supernatant $(1 \mathrm{~mL})$ of the PHMB/PBS/NaOH treated blood was combined with $1 \mathrm{M} \mathrm{HCl}(100 \mu \mathrm{L})$ before all samples were centrifuged for a further 5 min. The supernatant of each sample was then removed and stored at $-20^{\circ} \mathrm{C}$ until frozen and then transferred to $-80^{\circ} \mathrm{C}$ for later analysis.

A separate $2 \mathrm{~mL}$ of blood was collected into an EDTA tube and used for the determination of haemoglobin (via the cyanmethaemoglobin method) and haematocrit (via microcentrifugation) and used to estimate changes in plasma volume relative to baseline (9).

\section{Statistical analysis}

Data was analysed using SPSS 21.0 (SPSS Inc., Somers, NY, USA). Area under the curve (AUC) values were calculated using the trapezoidal method and were averaged over time. 
206 Correction of plasma measures for changes in plasma volume did not alter the results so the

207

208

209

210

211

212

213

214

215

216

217

218

219

220

221

222

223

224

225

226

227

228

unadjusted values are presented. All data were checked for normality of distribution using a Shapiro-Wilk test. Data containing one factor were analysed using a t-test or Wilcoxon signed-rank test, as appropriate. Data containing two variables were analysed using a twoway ANOVA, and where appropriate followed by Bonferroni-adjusted paired t-tests or Bonferroni-adjusted Wilcoxon signed-ranks, as appropriate. Data sets were determined to be significantly different when $P<0.05$. Data was found to be normally distributed, with the exception of all subjective appetite sensations, acylated ghrelin and GLP-1 $1_{(7-36)}$ and were subject to non-parametric statistical analysis. However, data has been presented as means \pm standard deviation for consistency throughout, unless stated otherwise.

\section{$\underline{\text { Results }}$}

Energy and macronutrient intake

A breakfast of $3095 \pm 195 \mathrm{~kJ}$ was provided during BC. Subsequent total ad-libitum energy intake was $11685 \pm 1893 \mathrm{~kJ}$ compared to $11329 \pm 2117 \mathrm{~kJ}$, for $\mathrm{BO}$ and $\mathrm{BC}$, respectively $(P=0.196)$. At lunch, energy intake was greater during BO $(5804 \pm 1817 \mathrm{~kJ})$ than BC $(4970 \pm$ $1987 \mathrm{~kJ} ; P<0.01$ ), whereas at dinner, there was a tendency for greater energy intake during $\mathrm{BC}(6359 \pm 1631 \mathrm{~kJ})$ than $\mathrm{BO}(5882 \pm 1443 \mathrm{~kJ} ; P=0.052)$. Including breakfast, total energy intake was $19 \pm 5 \%$ greater during BC $(14424 \pm 2255 \mathrm{~kJ})$ than BO $(11685 \pm 1893 \mathrm{~kJ})($ Fig. 1$)$.

Carbohydrate $(P<0.05)$ and fat $(P<0.05)$ intake was greater at lunch during $\mathrm{BO}$ compared to $\mathrm{BC}$, but there was no difference in protein $(P=0.142)$ or fibre $(P=0.314)$ intake. The dinner meal was homogenous in nature; therefore macronutrient selection could not be gauged from this meal. Including breakfast, total carbohydrate, protein and fibre intake were greater $(P<0.01)$ and fat intake tended to be greater $(P=0.068)$ during $\mathrm{BC}$ compared to BO (Table 1$)$. 
230 All appetite sensations (hunger, fullness, DTE and PFC) showed a main effect of trial $231(P<0.05)$, time $(P<0.001)$ and an interaction effect $(P<0.001 ;$ Fig. 2$)$. Subjects reported increased hunger, DTE and PFC, as well as lower fullness, in the post-breakfast period (0.5$4.5 \mathrm{~h})$ during $\mathrm{BO}$ compared to $\mathrm{BC}(P<0.01)$. Subjects also reported increased fullness at $7 \mathrm{~h}$ during $\mathrm{BO}$ compared to $\mathrm{BC}(P<0.05)$. For AUC analysis, data was divided into 3 sections; breakfast to lunch $(0-4.5 \mathrm{~h})$, lunch to dinner $(5-11 \mathrm{~h})$ and post dinner (11.5-24 h). These analyses revealed differences between trials for all subjective appetite variables between breakfast and lunch $(P<0.01)$. Fullness was also increased between lunch and dinner during BO compared to BC $(P<0.05$; Table 2$)$.

Steady state exercise and performance test

Total work completed during the performance test was greater during $\mathrm{BC}(314 \pm 53 \mathrm{~kJ})$ than BO $(300 \pm 56 \mathrm{~kJ} ; P<0.05$; Fig. 3). There was no effect of trial order on exercise performance $(P=0.297)$. During the 30 min steady state period, energy expenditure was greater during BO $(1407 \pm 210 \mathrm{~kJ})$ than $\mathrm{BC}(1330 \pm 191 \mathrm{~kJ} ; P<0.05)$. Fat oxidation was also greater during BO compared to $\mathrm{BC}(P<0.05)$, but there was no difference in carbohydrate oxidation between trials $(P=0.126)$. Average heart rate was higher during $\mathrm{BO}(155 \pm 9 \mathrm{bpm})$ than $\mathrm{BC}(151 \pm 8$ bpm; $P<0.001)$ during steady state, but was not different during the performance test $(P=0.397)$. There were no differences in RPE either during the 30 min steady state preload $(P=0.464)$ or the performance test $(P=0.712)$.

Blood parameters

250 Plasma glucose $(P<0.05)$, insulin $(P<0.001)$, acylated ghrelin $(P<0.001)$ and GLP-1 $1_{(7-36)}$ $(P<0.05)$ all showed a main effect of time. There were no main effects of trial or interaction 
effects for plasma glucose $(P \geq 0.201)$, acylated ghrelin $(P \geq 0.189)$ or GLP-1 ${ }_{(7-36)}(P \geq 0.056)$. There was an interaction effect for insulin $(P<0.01)$, with higher insulin concentrations at 4.5 h during $\mathrm{BC}$ than $\mathrm{BO}(P<0.01)$, while insulin concentrations tended to be higher at $9 \mathrm{~h}$ during BO compared to BC ( $P=0.073$; Table 3$)$.

\section{$\underline{\text { Discussion }}$}

The primary aim of this investigation was to determine the effect of breakfast omission/ consumption on subsequent energy intake and evening exercise performance. It was found that total work completed over a 30 min cycling performance test was reduced by approximately $4.5 \%$ following breakfast omission. Whilst energy intake was increased at lunch, this study also observed no difference in total ad-libitum energy intake between trials, resulting in a reduced total $24 \mathrm{~h}$ energy intake after breakfast omission. From a weight management perspective, occasional breakfast omission could be used as a viable means of energy restriction in habitual breakfast consumers, although this may slightly impair exercise performance. Further study is required to determine whether breakfast omission can be used chronically to assist with long term weight management.

The global increase in the prevalence of obesity has coincided with a gradual decline in breakfast consumption (15), with epidemiological evidence suggesting that those who regularly omit breakfast have a higher BMI than those who regularly consume breakfast (3). However, due to a number of confounding factors, including variations in activity patterns (6) and dietary profiles (14), there is a lack of causal data linking breakfast eating behaviour with energy balance. The results of the current investigation demonstrate that the total energy restricted at breakfast is not accurately compensated for over an acute $24 \mathrm{~h}$ period, resulting in a net energy deficit of $2738 \mathrm{~kJ}$. These findings are comparable with those of Levitsky and Pacanowski (22), who found total energy intake was reduced by approximately $1883 \mathrm{~kJ}$ 
following the omission of an ad-libitum breakfast meal. Similarly, 7 days consecutive breakfast omission was found to reduce energy intake by $670 \mathrm{~kJ} \cdot \mathrm{d}^{-1}$ on average compared to 7-days consecutive breakfast consumption (30). Taken collectively, data from these acute investigations suggest that, contrary to popular belief, breakfast omission does not lead to elevated energy intake over the course of the day, and as such there is potential for breakfast omission to be used in successful weight management strategies.

Consistent with previous findings, energy intake at lunch was greater during BO than BC $(1,19,22,30)$. Following the omission of breakfast, subjective appetite sensations were elevated throughout the morning compared to when breakfast was consumed (Fig. 2), and accordingly energy intake at lunch was increased by approximately $16 \%$. However, this modest increase in energy intake $(745 \pm 604 \mathrm{~kJ})$ only partially compensated for the energy deficit created by the omission of the breakfast meal $(3095 \pm 195 \mathrm{~kJ})$, and as such subjects remained in energy deficit throughout the afternoon. Similar to the findings in the current study, Levitsky and Pacanowski (22) reported elevations in hunger following the omission of an ab-libitum breakfast meal, leading to increased energy consumption at lunch. Hubert et al. (19) found that reducing breakfast energy intake by $1824 \mathrm{~kJ}$ resulted in an average elevation in energy intake at lunch of $500 \mathrm{~kJ}$. The average compensation at lunch for breakfast omission is remarkably consistent between these studies, with the current investigation revealing $24 \%$ compensation at lunch, compared to $22 \%$ (22) and $26 \%$ (19) previously reported.

Concentrations of the orexigenic hormone acylated ghrelin and the anorexigenic hormone GLP- $1_{(7-36)}$ are thought to respond to fluxes in energy balance $(8,17)$, and stimulate a behavioural response. In the current study, the increase in appetite observed throughout the morning period may have caused an increase in energy consumption during the time between breakfast and lunch in free-living conditions, as was found previously (25). Acylated ghrelin 
and GLP-1 $1_{(7-36)}$ were only measured $4 \mathrm{~h}$ after breakfast consumption/omission and immediately prior to exercise so the dynamic response of these hormones to feeding may have been missed. Following lunch, no differences were observed in subjective appetite sensations, which may suggest no difference in gut hormone concentrations. Accordingly, the appetitive responses to breakfast omission appear to be transient, and do not influence energy intake following the provision of lunch.

Whilst there is general agreement in the literature that breakfast omission reduces daily energy intake, two investigations contest these findings. Astbury et al. (1) found that the provision of a $1080 \mathrm{~kJ}$ breakfast was completely compensated for in the no breakfast condition at an ad-libitum lunch meal. This study was designed primarily to investigate the effect of breakfast on gastrointestinal hormonal regulation of food intake and incorporated a liquid pre-load between breakfast and lunch that may have influenced energy intake at lunch. Additionally, the provision of a low energy breakfast (10\% of daily energy requirements) has previously been shown to be more accurately compensated for at subsequent meals than higher energy breakfasts (31). Farshchi et al. (11) aimed to investigate whether the timing of breakfast consumption affected subsequent energy intake. Over a 2 week period, subjects either consumed cereal and milk at a traditional breakfast time (7-8am) or later in the day (12-12:30pm), which ensured that the energy provided was consistent across both interventions. Energy intake was found to be greater following breakfast omission compared to breakfast consumption. This was likely due to the experimental design, which does not necessarily represent typical practise for those utilising breakfast omission as a method of weight management.

It is well documented that consuming breakfast improves exercise performance in the morning compared omitting breakfast, i.e. exercising fasted $(32,33)$. The current study found that exercise performance was also compromised in the evening following breakfast omission 
in the morning, despite consuming lunch $4.5 \mathrm{~h}$ before exercise. Eating breakfast is highly

327

328 encouraged in the literature to maximise carbohydrate stores prior to competition (38), as glucose availability may be a limiting factor due to glycogen depletion (7). In particular, liver glycogen stores, which are important for blood glucose maintenance during exercise, have been shown to decrease by $\sim 40 \%$ following an overnight fast (36). Provision of a high carbohydrate breakfast will help replenish liver glycogen (16), and has been shown to increase muscle glycogen concentrations in the vastus lateralis by $11-17 \%(4,37)$. A recent study reported that $73 \%$ of female college athletes regularly omitted breakfast, resulting in suboptimal daily carbohydrate and energy intakes (34). This was also shown in the present study, as carbohydrate intake prior to exercise was reduced during BO compared to BC (148 \pm 65 vs. $259 \pm 73$ g), which may have influenced glucose availability and reduced exercise performance. It appears breakfast may play a central role in meeting daily carbohydrate requirements for exercising individuals and that consumption of breakfast might be important in order to maximise exercise performance thought the whole day.

Fat oxidation was greater during the 30 min steady state exercise period in BO. Increasing fat oxidation has been suggested to be beneficial for reducing fat mass and may also promote carbohydrate sparing, potentially improving performance (20). However, there was no difference in carbohydrate oxidation between trials therefore it is unlikely that glycogen sparing occurred during BO. Accordingly, energy expenditure was greater during BO, which may be attributable to an increase in dietary induced thermogenesis induced by greater energy intake at the previous ad-libitum lunch meal. An increased contribution of dietary induced thermogenesis to energy expenditure may also explain the higher heart rate observed during BO. Following food intake, the splanchnic tissues require an increase in blood supply to assist with the digestion and absorption of nutrients. Therefore, during sub-maximal exercise, an increase in cardiac output is required to meet the oxygen requirements of both 
the skeletal muscle and splanchnic tissues (39). Another indicator of sympathetic nervous activity is noradrenaline, which has been shown to peak after breakfast, with an attenuated response at subsequent feeding periods (29). Following the omission of breakfast, lunch becomes the first meal of the day. It could be considered that the sympathetic nervous response to feeding was greater following lunch during $\mathrm{BO}$ compared to $\mathrm{BC}$, thus heart rate was increased to a greater extent during steady state exercise. Noradrenaline also increases lipolysis (21) and may explain the elevation in fat oxidation during the steady state exercise on $\mathrm{BO}$.

A limitation with any research that investigates breakfast omission is the difficulty in blinding subjects to the study intervention. In the multifactorial 'central governor theory' model of fatigue described by Noakes (28), subject awareness of the study intervention may lead to an expectation in regard to exercise performance, and performance may decline as a result. This may be particularly pertinent with the current study as all subjects were habitual breakfast consumers, so the withdrawal of breakfast in the morning may have produced a particularly strong expectation of reduced performance. This may partially account for the findings in this study.

367 It has recently been shown that the omission of breakfast over a 6 week period has a negative effect on physical activity levels, reducing habitual physical activity thermogenesis on average by $1850 \mathrm{~kJ} \cdot \mathrm{d}^{-1}$ compared to when breakfast was consumed (2). Physical activity of this nature is difficult to manipulate or avoid as the nutritional intervention seemingly imposes a sub-conscious restriction on energy expenditure. Incorporating structured exercise into weight management programs may offset the magnitude of this deficit somewhat, provided adherence to exercise isn't affected. Whilst exercise performance might be important to maximise energy expenditure, the difference in exercise performance observed in the current study had a negligible influence on energy balance. Energy expenditure during 
the 30 min preload was $\sim 80 \mathrm{~kJ}$ greater during $\mathrm{BO}$, which was offset by an estimated reduction of energy expenditure of $\sim 70 \mathrm{~kJ}$ during $\mathrm{BO}$, assuming a cycling efficiency of $20 \%$ (18). Therefore net energy expenditure during exercise was almost identical between trials $(2898 \pm 307(\mathrm{BC})$ vs. $2905 \pm 307(\mathrm{BO}) \mathrm{kJ} ; P=0.834)$

In conclusion, the results of the present study demonstrate that occasionally omitting breakfast may be an effective method of reducing energy intake over a $24 \mathrm{~h}$ period in habitual breakfast consumers. However, exercise performance may be compromised throughout the whole day following the omission of breakfast in the morning. Therefore, for those concerned with maximising training and/or competition performance breakfast omission might impair performance or interfere with training adaptation.

\section{Acknowledgements}

This research was supported by the National Institute for Health Research (NIHR) Diet, Lifestyle \& Physical Activity Biomedical Research Unit based at University Hospitals of Leicester and Loughborough University. The views expressed are those of the authors and not necessarily those of the NHS, the NIHR or the Department of Health.

\section{Conflict of interests}

The authors would like to declare no conflicts of interest. The results of the present study do not constitute endorsement by the American College of Sports Medicine.

\section{References}

1. Astbury NM, Taylor MA, Macdonald IA. Breakfast consumption affects appetite, energy intake, and the metabolic and endocrine responses to foods consumed later in the day in male habitual breakfast eaters. $J$ Nutr. 2011;141(7):1381-9. 
2. Betts JA, Richardson JD, Chowdhury EA, Holman GD, Tsintzas K, Thompson D. The causal role of breakfast in energy balance and health: A randomized controlled trial in lean adults. Am J Clin Nutr. 2014; 100(2):539-47.

3. Cho S, Dietrich M, Brown CJP, Clark CA, Block G. The effect of breakfast type on total daily energy intake and body mass index: results from the Third National Health and Nutrition Examination Survey (NHANES III). J Am Coll Nutr. 2003; 22(4):296302.

4. Chryssanthopoulos C, Williams C, Nowitz A, Bogdanis G. Skeletal muscle glycogen concentration and metabolic responses following a high glycaemic carbohydrate breakfast. J Sports Sci. 2004; 22(11-12):1065-71.

5. Clayton DJ, Stensel DJ, Watson P, James LJ. The effect if post-exercise drink macronutrient content on appetite and energy intake. Appetite. 2014; 82: 173-9.

6. Cohen B, Evers S, Manske S, Bercovitz K, Edward HG. Smoking, physcal activity and breakfast consumption among secondary school students in a southwestern Ontario community. Canadian J Public Heal. 2003; 94(1):41-4.

7. Coyle EF, Coggan AR. Effectiveness of carbohydrate feeding in delaying fatigue during prolonged exercise. Sports Med. 1984; 1(6):446-58.

8. Cummings DE. Ghrelin and the short- and long-term regulation of appetite and body weight. Physiol Behav. 2006; 89(1):71-84.

9. Dill DB, Costill DL. Calculation of percentage changes in volumes of blood, plasma, and red cells in dehydration. J Appl Physiol. 1974; 37(2):247-8. 
419 10. Durnin JVGA, Womersley J. Body fat assessed from total body density and its

420

421

422

423

424

425

426

427

428

429

430

431

432

433

434

435

436

437

438 estimation from skinfold thickness: measurements on 481 men and women aged from 16 to 72 Years. Br J Nutr.1974; 32(01):77-97

11. Farshchi HR, Taylor MA, Macdonald IA. Deleterious effects of omitting breakfast on insulin sensitivity and fasting lipid profiles in healthy lean women. Am J Clin Nutr. 2005; 81(2):388-96.

12. Franz MJ, VanWormer JJ, Crain AL, et al. Weight-loss outcomes: a systematic review and meta-analysis of weight-loss clinical trials with a minimum 1-year follow-up. $J$ Am Diet Assoc. 2007; 107(10):1755-67

13. Frayn, K N. Calculation of substrate oxidation rates in vivo from gaseous exchange. $J$ Appl Physiol. 1983; 55(2):628-34.

14. Galvin MA, Kiely M, Flynn A. Impact of ready-to-eat breakfast cereal (RTEBC) consumption on adequacy of micronutrient intakes and compliance with dietary recommendations in Irish adults. Public Health Nutr. 2003; 6(4):351-63.

15. Haines PS, Guilkey DK, Popkin BM. Trends in breakfast consumption of US adults between 1965 and 1991. J Am Diet Assoc. 1996; 96: 464-70.

16. Hawley JA, Burke LM. Effect of meal frequency and timing on physical performance. Br J Nutr. 1997; 77 Suppl 1:S91-103.

17. Holst JJ. The physiology of glucagon-like peptide 1. Physiol Rev. 2007; 87(4):140939. 
18. Hopker JG, Coleman DA, Wiles JD. Differences in efficiency between trained and recreational cyclists. Appl Physiol Nutr Metab. 2007; 32(6):1036-42.

19. Hubert P, King NA, Blundell JE. Uncoupling the effects of energy expenditure and energy intake: appetite response to short-term energy deficit induced by meal omission and physical activity. Appetite. 1998; 31(1):9-19.

20. Jeukendrup A, Achten J. Fatmax : A new concept to optimize fat oxidation during exercise? Eur J Sport Sci. 2001; 1(5):1-5.

21. Klein S, Peters EJ, Holland OB, Wolfe RR. Effect of short and long-term $\beta$-adrenergic bloackade on lipolysis during fasting in humans. Am J Physiol. 1989; 257(1):E65-73.

22. Levitsky DA, Pacanowski CR. Effect of skipping breakfast on subsequent energy intake. Physiol Behav. 2013; 119:9-16.

23. Maraki M, Tsofliou F, Pitsiladis YP, Malkova D, Mutrie N, Higgins S. Acute effects of a single exercise class on appetite, energy intake and mood. Is there a time of day effect? Appetite. 2005; 45(3):272-8.

24. Marangoni F, Poli A, Agostoni C, Pietro P Di, Cricelli C. A consensus document on the role of breakfast in the attainment and maintenance of health and wellness. Acta Biomed. 2009; 80:166-71.

25. Martin A, Normand S, Sothier M, Peyrat J, Louche-Pelissier C, Laville M. Is advice for breakfast consumption justified? Results from a short-term dietary and metabolic experiment in young healthy men. Br J Nutr. 2000; 84(3):337-44. 
26. Mekary RA, Giovannucci E, Willett WC, Van Dam RM, Hu FB. Eating patterns and type 2 diabetes risk in men: Breakfast omission, eating frequency, and snacking. Am $J$ Clin Nutr. 2012; 95(5):1182-9.

27. Mifflin MD, St Jeor ST, Hill LA, Scott BJ, Daugherty SA, Koh YO. A new predictive equation in healthy individuals for resting energy. Am J Clin Nutr. 1990; 51:241-7.

28. Noakes TD. Fatigue is a brain-derived emotion that regulates the exercise behavior to ensure the protection of whole body homeostasis. Front Physiol. 2012; 3(82):113.

29. Panev P, Spiegel K, Marcinkowski T, Van Cauter E. Impact of carbohydrate-rich meals on plasma epinephrine levels: dysregulation with aging. J Clin Endocrinol Metab. 2005; 90(11):6198-206.

30. Reeves S, Huber JW, Halsey LG, Horabady-Farahani Y, Ijadi M, Smith T. Experimental manipulation of breakfast in normal and overweight/obese participants is associated with changes to nutrient and energy intake consumption patterns. Physiol Behav. 2014; 133:130-5.

31. Schusdziarra V, Hausmann M, Wittke C, et al. Impact of breakfast on daily energy intake--an analysis of absolute versus relative breakfast calories. Nutr J. 2011; 10(1):5.

32. Sherman WM, Brodowicz G, Wright DA, Allen WK, Simonsen J, Dernbach A. Effects of $4 \mathrm{~h}$ preexercise carbohydrate feedings on cycling performance. Med Sci Sports Exerc. 1989; 21(5):598-604.

33. Sherman WM, Peden CM, Wright DA. Carbohydrate feedings $1 \mathrm{~h}$ before improves cycling performance exercise. Am J Clin Nutr. 1991; 54:866-70. 
34. Shriver LH, Betts NM, Wollenberg G. Dietary intakes and eating habits of college athletes: are female college athletes following the current sports nutrition standards? $J$ Am Coll Health. 2013; 61(1):10-6.

35. Stunkard AJ, Messick S. The three-factor eating questionnaire to meaasure dietary restraint, disinhibition and hunger. J Psychosomatic Res. 1985; 29(I):71-83.

36. Taylor R, Magnusson I, Rothman DL, et al. Direct Assessment of Liver Glycogen Storage by 13 C Nuclear Magnetic Resonance Spectroscopy and Regulation of Glucose Homeostasis after a Mixed Meal in Normal Subjects. J Clin Invest. 1996; 97(1):126-32.

37. Wee S-L, Williams C, Tsintzas K, Boobis L. Ingestion of a high-glycemic index meal increases muscle glycogen storage at rest but augments its utilization during subsequent exercise. J Appl Physiol. 2005; 99(2):707-14.

38. Williams C, Serratosa L. Nutrition on match day. J Sports Sci. 2006; 24(7):687-97.

39. Yi JJ, Fullwood L, Stainer K, Cowley AJ, Hampton JR. Effects of food on the central and peripheral haemodynamic response to upright exercise in normal volunteers. $\mathrm{Br}$ Heart J. 1990; 63(1):22-5.

40. Zullig K, Ubbes VA, Pyle J, Valois RF. Self-reported weight perceptions, dieting behavior, and breakfast eating among high school adolescents. J Sch Health. 2006; 76(3):87-92. 
500 Table 1. Carbohydrate $(\mathrm{CHO})$, protein $(\mathrm{PRO})$, fat, fibre and water intake over the course of 501 the each trial.

\begin{tabular}{|c|c|c|c|c|c|c|}
\hline & Energy (kJ) & CHO (g) & PRO (g) & FAT (g) & FIBRE (g) & WATER $(\mathrm{ml})$ \\
\hline \multicolumn{7}{|c|}{ Breakfast } \\
\hline BC & $3095 \pm 195$ & $130.3 \pm 8.2$ & $19.5 \pm 1.2$ & $13.9 \pm 0.9$ & $4.5 \pm 0.3$ & $625 \pm 39$ \\
\hline BO & $0 \pm 0$ & $0^{\dagger}$ & $0^{\dagger}$ & $0^{\dagger}$ & $0^{\dagger}$ & $625 \pm 39$ \\
\hline \multicolumn{7}{|c|}{ Lunch } \\
\hline BC & $4970 \pm 1987$ & $128.5 \pm 69.0$ & $44.3 \pm 22.8$ & $52.7 \pm 20.2$ & $10.2 \pm 4.5$ & $814 \pm 211$ \\
\hline BO & $5804 \pm 1878^{\dagger}$ & $148.1 \pm 65.1^{\dagger}$ & $50.2 \pm 22.2$ & $63.3 \pm 23.9^{\dagger}$ & $11.1 \pm 4.2$ & $894 \pm 207$ \\
\hline \multicolumn{7}{|c|}{ Dinner } \\
\hline BC & $6359 \pm 1631$ & $194.2 \pm 49.8$ & $53.6 \pm 13.7$ & $55.9 \pm 14.3$ & $9.7 \pm 2.5$ & $477 \pm 121$ \\
\hline BO & $5882 \pm 1443$ & $179.6 \pm 44.1$ & $49.5 \pm 12.2$ & $51.7 \pm 12.7$ & $9.0 \pm 2.2$ & $443 \pm 108$ \\
\hline \multicolumn{7}{|c|}{ Total } \\
\hline BC & $14424 \pm 2255$ & $453.0 \pm 80.9$ & $117.4 \pm 24.9$ & $122.5 \pm 19.7$ & $24.4 \pm 5.5$ & $3395 \pm 627$ \\
\hline BO & $11685 \pm 1893^{\dagger}$ & $327.8 \pm 78.3^{\dagger}$ & $99.7 \pm 25.0^{\dagger}$ & $115.1 \pm 17.6$ & $20.1 \pm 5.5^{\dagger}$ & $3335 \pm 489$ \\
\hline
\end{tabular}


Table 2. Time averaged area under the curve for each appetite variable.

507

508

509

510

511

512

513

514

515

516

517

518

519

520

\begin{tabular}{ccc}
\hline Post & Post & Post \\
breakfast & lunch & dinner
\end{tabular}

$\begin{array}{ccc}(0-4 \mathrm{~h}) & (5-10.5 \mathrm{~h}) \quad(11-24 \mathrm{~h}) \\ \text { Hunger }\left(\mathrm{mm} \cdot \mathrm{h}^{-1}\right)\end{array}$

BC $38 \pm 15 \quad 39 \pm 13 \quad 44 \pm 16$

BO $72 \pm 18^{\dagger} \quad 35 \pm 16 \quad 37 \pm 14$

Fullness $\left(\mathbf{m m} \cdot \mathbf{h}^{-1}\right)$

$\begin{array}{cccc}\text { ВC } & 47 \pm 13 & 56 \pm 13 & 49 \pm 17 \\ \text { BO } & 12 \pm 9^{\dagger} & 62 \pm 12^{\dagger} & 46 \pm 15\end{array}$

DTE $\left(\mathbf{m m} \cdot \mathbf{h}^{-1}\right)$

BC $\quad 45 \pm 18 \quad 41 \pm 13 \quad 41 \pm 15$

BO $76 \pm 21^{\dagger} \quad 35 \pm 16 \quad 38 \pm 11$

PFC $\left(\mathbf{m m} \cdot \mathbf{h}^{-1}\right)$

BC $47 \pm 16 \quad 44 \pm 12 \quad 44 \pm 13$

BO $71 \pm 20^{\dagger} \quad 43 \pm 13 \quad 40 \pm 15$

Data are means \pm standard deviations. ${ }^{\dagger}$ values are significantly different to $\mathrm{BC}(P<0.05)$. 
521 Table 3. Plasma concentrations of glucose, insulin, acylated ghrelin and GLP-1 $(7-36)$ over the 522 course of the trial during $\mathrm{BC}$ and $\mathrm{BO}$.

Pre-breakfast (0 h)

Pre-lunch $(4.5 \mathrm{~h})$

Pre-exercise $(9$ h)

\section{Glucose $\left(\mathbf{m m o l} \cdot \mathbf{L}^{-1}\right)$}

$\begin{array}{llll}\text { BC } & 5.33 \pm 0.18 & 4.89 \pm 0.42 * & 5.27 \pm 0.39 \\ \text { BO } & 5.18 \pm 0.25 & 4.91 \pm 0.33 * & 5.13 \pm 0.67\end{array}$

\section{Insulin $\left(\mu \mathrm{IU} \cdot \mathbf{m L}^{-1}\right)$}

$\begin{array}{lccc}\text { ВC } & 15.0 \pm 4.4 & 16.1 \pm 5.8 & 24.2 \pm 6.8 * \\ \text { BO } & 13.9 \pm 3.5 & 10.7 \pm 4.1^{\dagger} * & 30.7 \pm 11.5 *\end{array}$

\section{Acylated Ghrelin $\left(\mathrm{pg} \cdot \mathrm{mL}^{-1}\right)$}

$\begin{array}{cccc}\text { BC } & 108 \pm 114 & 115 \pm 65 & 92 \pm 90 \\ \text { BO } & 97 \pm 99 & 118 \pm 121 * & 71 \pm 94 *\end{array}$

\section{$\operatorname{GLP}_{(7-36)}\left(\mathbf{p m o l} / \mathrm{L}^{-1}\right)$}

$\begin{array}{llcc}\text { BC } & 7.22 \pm 6.06 & 9.85 \pm 9.30 & 8.51 \pm 7.29 \\ \text { BO } & 6.61 \pm 6.41 & 6.55 \pm 6.82 & 12.99 \pm 12.26 \text { * }\end{array}$

523 Normal and non-normally distributed data are presented as means \pm standard deviations for 524 consistency. ${ }^{\dagger}$ indicates values are significantly different to $\mathrm{BC}$; * indicates values are 525 significantly different compared to baseline $(P<0.05)$. 
528 Figure 1. Energy intake $(\mathrm{kJ})$ at each ad-libitum meal and over $24 \mathrm{~h}$ during BC ( $\mathbf{})$ and BO 529 ( $\square)$. Left panel displays mean values with vertical error bars representing standard deviation. 530 Right panel shows individual subjects energy intake response at each ad-libiutm meal. $†$ 531 indicates values are different to $\mathrm{BC}(P<0.05)$.
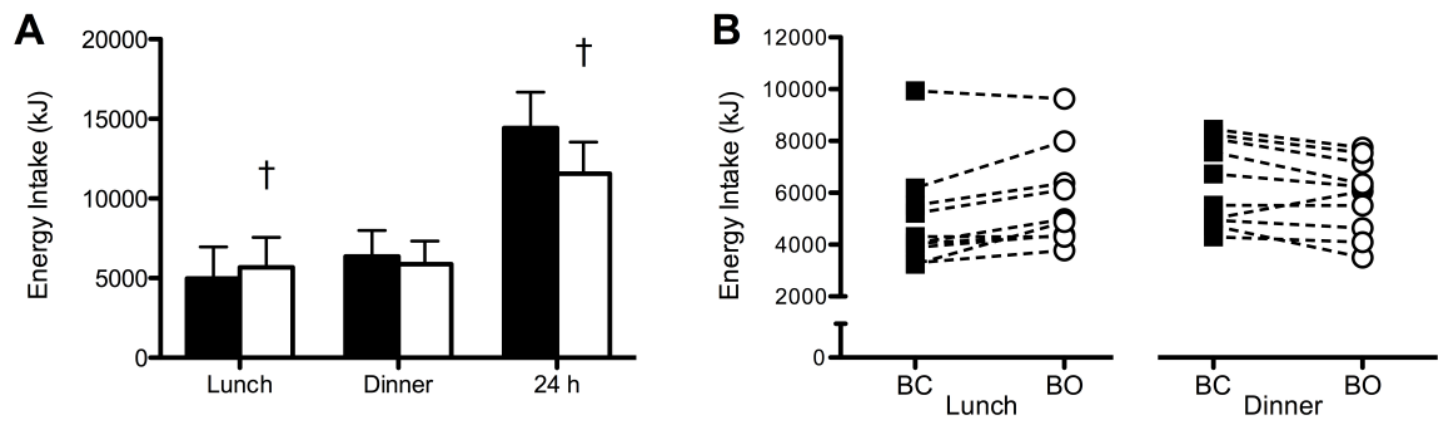

532 
550 Figure 2. Subjective sensations of hunger (A), fullness (B), desire to eat (DTE) (C) and 551 prospective food consumption (PFC) (D) during BC (a) and BO (०). Data points are means

552 with vertical error bars representing standard error of the mean. White rectangle indicates 553 standard meal feeding, vertical hatched rectangles indicate an ad-libitum meal, and black 554 rectangle indicates exercise period. All appetite variables showed a main effect of time. $†$ 555 indicates values are significantly different between trials $(P<0.05)$.

A

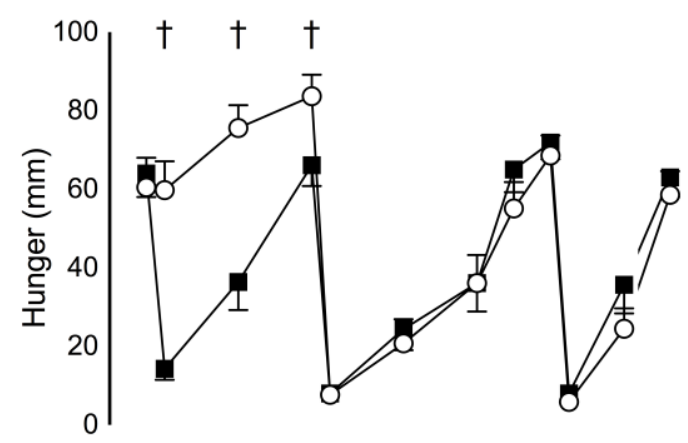

C

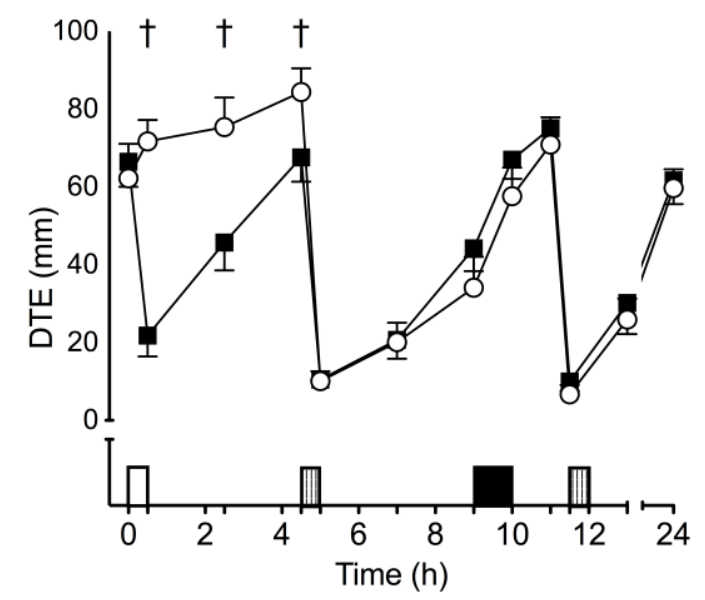

B

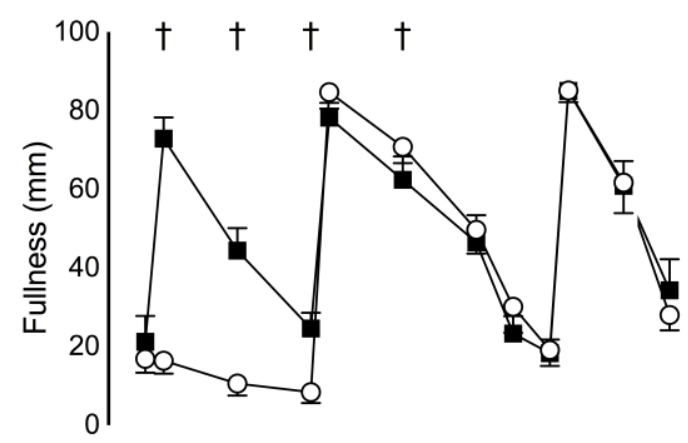

D

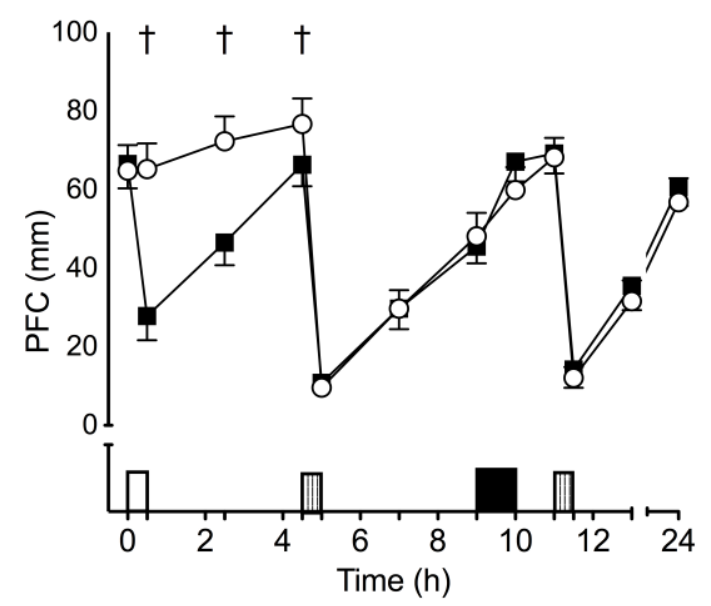

556 
561 Figure 3. Work completed $(\mathrm{kJ})$ during the exercise performance test. Left panel displays 562 mean work completed during BC (a) and BO ( $\square$ ) with vertical error bars representing 563 standard deviation. Right panel displays individual subject's performance during BC ( $\mathbf{a})$ and $564 \mathrm{BO}(\circ) . \dagger$ indicates values are significantly different to $\mathrm{BC}(\mathrm{P}<0.05)$.

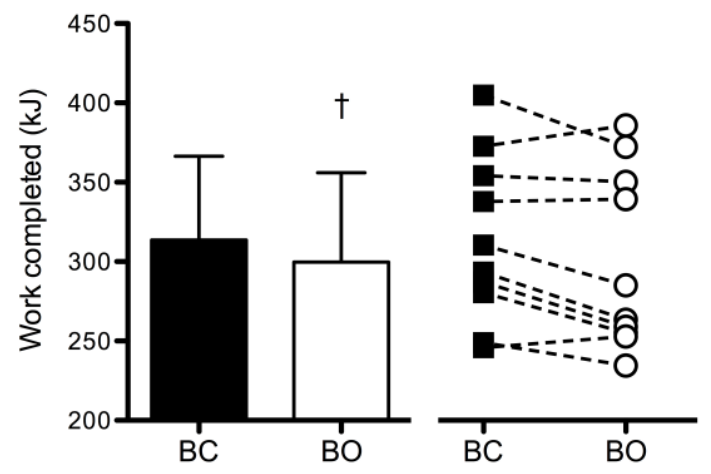

565

566

567

568

569

570

571

572 